\title{
The usage of photoelectric modules in the outdoor lighting system of university building
}

\author{
Bator B. Tsybikov ${ }^{1, *}$, Lyudmila P. Sumarokova ${ }^{1}$ \\ ${ }^{1}$ National Research Tomsk Polytechnic University, 634050 Tomsk, Russia
}

\begin{abstract}
The paper presents the usage of solar panels for lighting system of university building and there is a cost sheet of all necessary equipment: spotlights, controller, panels, batteries. The lighting systems are related to low-power consumers. At nights and unsunny weathers of lithium-ion batteries work after charging.
\end{abstract}

\section{Introduction}

The biggest part of Russian territory has favourable climatic conditions for solar energy consumption. In south regions, length of solar radiation is in the range from 2000 to 4000 hours a year and annual amount of solar energy on a horizontal surface is between 1280 and 1870 Kilowatt-hour/meter ${ }^{2}[1]$. The usage of solar electricity has many advantages. Nowadays, the such electricity is widely used in remote areas where is no centralized electric power supply, solar batteries are used for electricity supply of cottages, water pumps and so on [2]. The aim of this study is a operation of outdoor lighting system of $8^{\text {th }}$ TPU university building based on photoelectric power sources. An autonomous solar power plant includes: photoelectric modules, storage batteries, electronic unit, comprising controller, which tracks of battery`s work, then charging unit and inverter for transformation a direct current into alternating current $220 \mathrm{~V}$ with frequency $50 \mathrm{~Hz}$.

Rated power of photoelectric modules provides necessary energy production for uninterrupted work of street lightning during the whole day. At nights, usage of batteries is expected to. Surplus of power transfers to extra ballast resistance.

Block scheme of the autonomous electric supply`s street lighting in $8^{\text {th }}$ university building can be seen in Figure 1.

Information channels are marked with stippled lines [3], Power channels with solid ones.

\footnotetext{
* Corresponding author: tytyt1993@,mail.ru
} 


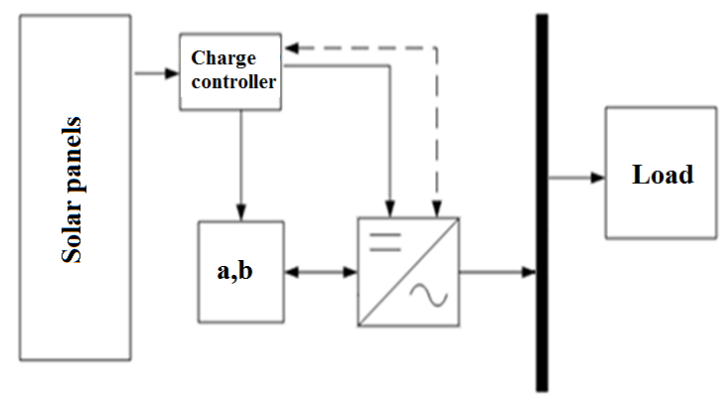

Fig. 1. Block scheme of the autonomous electric supply`s street lighting in 8th university building.

\section{Calculation}

For definition of the best solution of architectural highlight of university $8^{\text {th }}$ building`s front, comparison study was made for three lighting units with different powers: PSD-70, NL-60, PSD-30. As a result of the comparison, it was offered to use 36 LED spotlights PSD-70, intended for indoor and outdoor lighting of industrial installation, inside courtyard space and building yard.

Rated power consumed by the LED spotlights is $P_{\text {heat }}=0.07 \cdot 36=2.52 \mathrm{kWatt}$.

Average consumption of electricity during seasons a day is: in spring 24, 86 $\mathrm{kWatt} \cdot$ hour, in summer $18.63 \mathrm{kWatt} \cdot \mathrm{hour}$, in autumn $34.03 \mathrm{kWatt} \cdot \mathrm{hour}$, in winter 40.27 $\mathrm{kWatt} \cdot$ hour.

The project of street lighting of 8th university building`s front at the side of the intersection of Usova Street and Sovetskaya street was simulated in DIALux program. It can be seen in Figure 2.

Silicone single-crystal solar units from Yingli PANDA Solar firm with modules YL300C-30b, 300 Watts were used as photoelectric modules.

Determination of necessary number of moduleswas executed in 3 stages:

1. The total square of solar modules $S_{\Sigma}^{\mathrm{sp}}$ was defined forrequired energy production and steady maintenance work of lighting system in December. This winter month is characterized by the most unfavorable conditions for generating electricity and consumption - few daylight hours and big value of energy consumption.

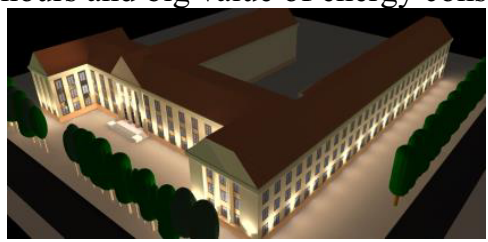

Fig. 2. Outdoor lighting of the front with spotlights PSD-70.

2. Square of one standard panel $\mathrm{S}_{1 \mathrm{sp}}$ is equal:

$$
\mathrm{S}_{1 \mathrm{sp}}=\mathrm{a} \cdot \mathrm{b}
$$

where $\mathrm{a}$ - length of a solar panel, $\mathrm{b}$ - width;

3. The number of solar panels is defined by division of required total square of solar panels $\mathrm{S}_{\Sigma}{ }^{\text {sp }}$ into the value of one standard panel $\mathrm{S}_{1 \text { сп }}$. 


$$
\mathrm{n}_{\mathrm{sp}}=\frac{\mathrm{s}_{\Sigma}^{\mathrm{sp}}}{\mathrm{s}_{1 \mathrm{sp}}}
$$

$\mathrm{N}_{\mathrm{sp}}$ - number of solar panels.

As a result of the study, it was decided to set up photoelectric modules at an angle $\beta=$ $80^{\circ}$ to the horizon and south-orientation, which allowed significantly increase energy production during the period November to February. LED spotlights are used as source of light. Measures were taken to optimize energy production through disconnection half of spotlights after 22.00 hours and it was achieved to reduce energy consumption in winter season to $32.7 \%$ and $33 \%$ in autumn term.

Main technological characteristics of solar power plant: power of photoelectric modules - 21.6 kWatt, one voltage inverter, 7 charge controllers, 64 lithium-ion batteries, 36 LED spotlights each power 70 Watts and copper cables of mark VVGng $3 \times 6 \mathrm{~mm}^{2}$.

\section{Conclusions}

In this study, the possibility of using helio-energy resources have been analyzed in the context of street lighting of TPU university building.

The energy production of the autonomous solar power plant was determined per year with using of hourly average and daily average calculations [4]. The performed calculation shows the opportunity and appropriateness of using solar panels to generate electricity for low-power consumers in the climatic conditions of the Tomsk region.

\section{References}

1. A. Yurchenko, A. Kozlov, A. Volkov, Photovoltaic Solar Energy: Proc. of XXII European Conf. Valencia, 2989( 2008)

2. L.P. Sumarokova, Naukovedenie, 8,(6) 11 (2016) [in Russian]

3. M.A. Surkov, Naukovedenie, 8,(4) 13 (2016) [in Russian]

4. B.V. Lukutin, E.B. Shandarova, A.F. Makarova, I.B. Shvartsman, Urgent problems of modern mechanical engineering, 12005 (2016) 